УДК 811.111 '373.612.2’42: [32:316.658

DOI https://doi.org/10.26661/2414-1135-2021-84-28

\title{
КОГНІТИВНІ АСПЕКТИ ІНТЕРПРЕТАЦІЇ МЕТАФОРИ В ПОЛІТИЧНОМУ ДИСКУРСІ (НА МАТЕРІАЛІ ІНАВГУРАЦЙНОӤ ПРОМОВИ ДЖ. БАЙДЕНА)
}

\author{
Печко Н. М. \\ кандидат філологічних наук, дочент, \\ дочент кафедри іноземних мов та перекладу \\ Волинський національний університет імені Лесі Украӥнки \\ просп. Волі, 13, Луцьк, Волинська область, Украӥна \\ orcid.org/0000-0001-6084-8693 \\ pechko.nina@vnu.edu.ua \\ Харкевич Г. I. \\ кандидат філологічних наук, дочент, \\ дочент кафедри іноземних мов та перекладу \\ Волинський національний університет імені Лесі Украӥнки \\ просп. Волі, 13, Луиььк, Волинська область, Украӥна \\ orcid.org/0000-0001-6681-5251 \\ kharkevych.halyna@vnu.edu.ua
}

\begin{abstract}
Ключові слова: політична промова, метафоризачія, концептуальна метафора, індивідуально-авторська метафора.
\end{abstract}

Когнітивна лінгвістика трактує метафору як ідеальну модель мовного відображення базового когнітивного процесу. Вона $\epsilon$ універсальним знаряддям мислення та пізнання світу. У політичному дискурсі метафора виступає непрямим засобом впливу на суспільну свідомість, метою якого $\epsilon$ створення політичного іміджу, формування переконань та уявлень, продукування позитивної чи негативної емоційно-оцінної позиції. Отже, дослідження метафори та метафоризації в когнітивно-дискурсній парадигмі $\epsilon$ перспективним і актуальним напрямом сучасних лінгвістичних студій. У статті розглянуто концептуальні аспекти метафоризації англійського політичного дискурсу. Предметом детального аналізу $\epsilon$ когнітивні та комунікативно-прагматичні особливості метафоричних засобів, використаних в інавгураційній промові Джозефа Байдена. Виокремлено базові концептуальні метафори (UNITY IS A PURPOSE, HISTORY IS A STORY, HISTORY IS A PERSON, NATION IS AN ORGANISM, DEMOCRACY IS A WAR), які формують рамковий пропозиційний зміст політичної промови. Ці концептуальні метафори реалізуються через низку метафоричних засобів, серед яких такі: метафора-кліше, метонімія, персоніфікація, порівняння, індивідуально-авторська метафора. Фактичний матеріал підтверджує домінування оригінальної індивідуально-авторської метафори в політичному дискурсі президента, найоптимальнішим способом передачі якої є дослівний переклад із застосуванням абсолютних та відносних еквівалентів. Дослідження використаних політичних метафор здійснювалося 3 позиції аналізу лінгвістичних образних виразів як елементів індивідуального авторського стилю американського політичного лідера - Джозефа Байдена. Визначено комунікативну та прагматичну спрямованість використаних метафоричних засобів. Запропоновано ефективні стратегії передачі використаних американським президентом Дж. Байденом англійських концептуально-образних прийомів засобами української мови зі збереженням їхнього семантичного, прагматичного та стилістичного потенціалу. 


\title{
COGNITIVE ASPECTS OF METAPHOR INTERPRETATION IN POLITICAL DISCOURSE (BASED ON THE INAUGURAL ADDRESS BY JOSEPH R. BIDEN)
}

\author{
Pechko N. M. \\ Candidate of Philological Sciences, Associate Professor, \\ Associate Professor at the Department of Foreign Languages and Translation \\ Lesya Ukrainka Volyn National University \\ Voli ave., 13, Lutsk, Volyn region, Ukraine \\ orcid.org/0000-0001-6084-8693 \\ pechko.nina@vnu.edu.ua \\ Kharkevych H. I. \\ Candidate of Philological Sciences, Associate Professor, \\ Associate Professor at the Department of Foreign Languages and Translation \\ Lesya Ukrainka Volyn National University \\ Voli ave., 13, Lutsk, Volyn region, Ukraine \\ orcid.org/0000-0001-6681-5251 \\ kharkevych.halyna@vnu.edu.ua
}

Key words: political speech, metaphorization, conceptual metaphor, original individual metaphor.
Cognitive linguistics treats metaphor as an ideal model of the basic thinking process reflected in the linguistic means. It is a universal tool of cognition, reasoning and understanding the world. In the political discourse, metaphor is viewed as an indirect way of shaping public opinion aimed at building up a political image, establishing views and beliefs, producing emotionally evaluative judgment, either a positive or a negative one. Therefore, the research of metaphor and metaphorization in the cognitive discourse paradigm is a relevant and prospective field of modern linguistic studies.

The article deals with the conceptual aspects of the English political discourse metaphorization. The detailed analysis refers to the cognitive and communicative-pragmatic peculiarities of the figurative expressions employed by Joseph Biden in his inaugural address. In the course of studies, the fundamental conceptual metaphors (UNITY IS A PURPOSE, HISTORY IS A STORY, HISTORY IS A PERSON, NATION IS AN ORGANISM, DEMOCRACY IS A WAR) constituting the propositional content frame of his political speech have been determined. The conceptual metaphors in question are manifested through a number of figurative means such as metaphor-cliché, metonymy, personification, simile, and original individual metaphor. The material analyzed proves the dominance of the latter one in the President's political discourse. The most efficient way of rendering this kind of metaphor into the target language is by literal translation, with applying absolute and relative equivalents. The research of the political metaphors has been conducted from the perspective of figurative linguistic means as constitutive elements of the American political leader - Joseph Biden's authentic style. The authors suggested effective translation strategies of conveying the English figurative means utilized by the American President Joseph Biden into Ukrainian, not adversely affecting their semantic, pragmatic and stylistic potential. 
Постановка проблеми. Політичний дискурс як складне комунікативно-стилістичне утворення охоплює широкий спектр усних та письмових текстів, згенерованих політичними суб' єктами 3 метою здійснення впливу на суспільну свідомість, формування конкретних переконань і уявлень, просування політичних ідей та реалізації політичних намірів. Комунікативна спрямованість політичного дискурсу чітко визначена, часто має маніпулятивний характер та використовує широкий спектр лінгвістичних засобів для реалізації іiі прагматичної складової частини. Використання метафоричного мовлення, яке підсилює експресивність політичних промов, у цьому аспекті привертає неабияку увагу лінгвістів.

Політичне мовлення має свої визначальні характеристики і зазвичай трактується як таке, що проходить підготовку, супровід, піддається контролю, нагляду, виправдовується, оцінюється та критикується (C. Shaffner) [1, с. 201]. Воно викликає прискіпливу увагу спеціальних аналітиків та широкого загалу, а також нестримне бажання авторів політичних промов відійти від чітких прямолінійних висловлювань та використати метафоричні засоби, прагнучи досягти бажаної стилістичної експресії, з одного боку, та, породжуючи багатозначний імпліцитний зміст. з іншого.

Стиль кожного окремого політика вирізняється певним багажем метафоричних засобів, зокрема й мовленнєвих (індивідуально-авторські) метафор, які спрямовані на реалізацію конкретного комунікативного завдання та досягнення бажаного перлокутивного ефекту. Аналіз таких засобів сприяє розумінню семантики політичного дискурсу та його комунікативної інтенції.

У цьому ракурсі в лінгвістичних дослідженнях простежуються декілька паралельних напрямів, у центрі уваги яких перебуває метафоризація політичного дискурсу. Варто виокремити когнітивний підхід, у рамках якого досліджується концептуальна метафора дискурсу (Н.Д. Арутюнова, T.R. Burkholder, T.A. van Dijk, G. Lakoff, M. Johnson, Z. Kövecses, Z. Pavlikova), семантично-прагматичний підхід вивчення мовних та мовленнєвих метафор (А.П. Гаврилюк, J. Charteris-Black, A. Musolff), перекладознавчі студії, які аналізують шляхи передачі метафоричних засобів політичного дискурсу засобами мови перекладу (О. Жулавська, Н.В. Лягушкіна, С.В. Шикалов, P. Dvorak, P. Newmark).

Метою статті $\epsilon$ когнітивний аналіз інавгураційної промови Джозефа Байдена як одиниці політичного дискурсу, що передбачає вирішення низки практичних завдань: визначення базових концептуальних метафор промови та мовленнєвих метафор як елементів індивідуального авторського стилю, їх типологізація за стилістич- ною ознакою, інтерпретація їхньої комунікативно-прагматичної спрямованості та визначення оптимальних стратегій передачі використаних американським президентом концептуально-образних прийомів засобами української мови зі збереженням їхнього семантичного та стилістичного потенціалу.

Предмет і об'єкт дослідження. Предметом дослідження $є$ метафоризація англійського політичного дискурсу. Об'єктом дослідження є концептуальні метафори, які формують когнітивну основу інавгураційної промови, та їхня текстово-дискурсна реалізація у формі метафоричних засобів, стратегії їх перекладу.

Виклад основного матеріалу. В англійській мові метафоричні засоби вживаються досить широко, адже вони сприяють передачі та сприйняттю інформації в доступнішій формі, пояснюють складні поняття, привертають увагу аудиторії до поставленої проблеми. Це значною мірою підтверджується політичним дискурсом - виборчими промовами, парламентськими виступами, заявами, дебатами, урочистими зверненнями, де метафоризація лінгвістичних одиниць досягає значного рівня.

$\mathrm{y}$ широких мовознавчих колах традиційно метафора трактується як художній засіб, стилістичний прийом, що полягає в переносному вживанні слова чи виразу на основі аналогії, схожості або порівняння, а також слово, вираз, ужиті таким способом [2]. Метафора виконує декілька функцій, залежно від яких вона може розглядатись як стилістичний прийом, як спосіб образного вираження змісту, як спосіб пізнання та номінації нових понять [3]. Метафори передають різноманітні конотації, асоціації та зв'язки, реалізують естетичну й емоційно-оцінну функцію. Як зазначає X. Шумахер, метафори міцно вплетені в полотно мови, яка була б без них бляклим шматком тканини $[4$, с. 1$]$.

У сучасних лінгвістичних студіях підхід до вивчення метафори базується на когнітивних аспектах функціонування цієї лінгвоконцептуальної одиниці та можливостях її передачі в рамках досліджень перекладознавчих студій. Прихильники такого підходу ідентифікують метафору як процес зіставлення (mapping) двох різних концептуальних доменів: цільового домену (target domain) (концептуальна ідея, яка описується метафорою) та вихідного домену (source domain) (концептуальна одиниця, яка використовується для створення метафоричної конструкції) [5, с. 4; 6, с. 528]. Відбувається накладання двох об'єктів чи явищ із різних концептуальних класів шляхом особливого використання мови, метою якого є краще донесення їхніх характерних ознак та розкриття їхньої сутності, що сприяє кращому розумінню [7, с. 98]. 
Використання метафор у когнітивній сфері як аналітичного інструменту свого часу було детально розроблено Дж. Лакоффом і М. Джонсоном, які стверджували, що наша звичайна концептуальна система значною мірою метафорична. Усі наші думки і знання або виникають безпосередньо 3 нашого чуттєвого досвіду, або усвідомлені та структуровані в термінах інших понять [8]. Зокрема, метафори відіграють ключову роль у конструюванні соціальної та політичної реальності. Концептуальні метафори забезпечують відтворення певних асоціативних комплексів, виводять на передній план елементи смислу, які раніше не бралися до уваги, і приховують ті, які втратили свою актуальність [5, с. 6].

Тривалий час використання метафоричних засобів у політичному дискурсі мало двозначне тлумачення. Окремі лінгвісти вказували на небезпеку надмірної метафоризації висловлювань, що може викликати інтелектуальне та політичне збентеження: "leading human mind into intellectual and political confusion" [9, с. 1]. Однак пізніше в різних лінгвістичних, психологічних та філософських дискусіях було доведено ефективність та релевантність використання метафори для соціальної та політичної концептуалізації.

Наприклад, у результаті проведеного аналізу передвиборчих промов двох ключових кандидатів, Д. Трампа та Дж. Байдена, під час президентської кампанії е США дослідниця Ж. Павлікова виокремила низку концептуальних метафор, наявних у їхній риториці: ECONOMY IS A BUILDING; POLITICS IS WAR; ELECTIONS ARE WAR; COUNTRY IS A PERSON; COUNTRY IS A PLANT; COUNTRY IS A BUILDING; NATION IS A PERSON [10, с. 318-319]. Концептуальні метафори актуалізуються в тексті шляхом використання широкого спектра метафоричних засобів: метафор, метонімій, персоніфікацій, порівнянь.

Зосередимось на особливостях політичної риторики Джозефа Байдена. Ні в кого не викликає сумніву, що цей політичний лідер, який пройшов довгий шлях політичного кар'єрного росту та професійного досвіду, вибудував певний стиль спілкування 3 політично заангажованою аудиторією, який є досить дипломатичним та водночас оптимально ефективним для нього, тобто сприяє реалізації певних політичних завдань. На відміну від його попередника Д. Трампа, дискурс Дж. Байдена чітко структурований, вирізняється логічністю та зв'язністю. Иого заяви та звернення до нації є змістовними, концептуально-ідейними та прагматично виваженими. Висловлювання новообраного президента мають прямолінійний характер, він не намагається пом'якшити свою риторику, коли йдеться про серйозні речі чи проблеми, але доносить свої ідеї 3 оптимістичною нотою. Н. Spencer зазначає: "He didn't sugarcoat anything, but did it in a very positive way" [11]. Дж. Байден ідентифікує виклики, які стоять перед країною, як-от "political extremism, white supremacy and domestic terrorism", та паралельно окреслює шляхи їх вирішення, імпліцитно критикує колишнього президента Д. Трампа, не називаючи його імені. Водночас у своїй політичній риториці він вдається до вживання особових займенників, a саме I, you, we, що рідко трапляється в політичних промовах та своєрідним чином наближує спікера до аудиторії, перетворює офіційний виступ на таку собі відверту розмову. Автентичний стиль спілкування Джозефа Байдена відзначається простотою, дружелюбністю та наближеністю до народу; американські аналітики характеризують його як "folksy style" [12]. Його особлива риса - це використання простих звертань ("Look, folks") та колоквіалізмів ("I get it"), що, безумовно, викликає емпатію та підтримку цільової аудиторії та, як наслідок, сповна реалізує прагматичну складову частину дискурсу мовця.

Центральною ідеєю інавгураційної промови Джозефа Байдена було об'єднання нації. Тобто базовою концептуальною метафорою його виступу є UNITY IS A PURPOSE. У текстовому форматі вона маніфестується через низку стилістичних прийомів та метафоричних засобів, які ретранслюють цю ідею на пропозиційному рівні. А саме:

1. $<\ldots>$ my whole soul is in this: Bringing America together (метонімія).

2. Uniting to fight the common foes we face (метафора-кліше):

Anger, resentment, hatred.

Extremism, lawlessness, violence.

Disease, joblessness, hopelessness.

3 . This is our historic moment of crisis and challenge, and the unity is the path forward (оригінальна індивідуально-авторська метафора).

Американська нація сприймається як живий організм - NATION IS AN ORGANISM, здатний рости, процвітати, рухатись або занепадати. Це підтверджується низкою персоніфікацій:

1. America has risen to the challenge. - Америка (американський народ) прийняла виклик. Приклад використання метонімії з повним збереженням образу під час перекладу.

2. Over the centuries through storm and strife, in peace and in war, we have come so far. - Позаду нас важкі століття бід та боротьби, миру та війн, ми пройшли / подолали довгий шлях.

3. To overcome these challenges - to restore the soul and to secure the future of America - requires more than words. - Щоб подолати ці виклики - зцілити душу нації та гарантувати світле майбутнє Америці - потрібно більше, ніж слова. 
Застосовано дослівний переклад із додаванням семантичних компонентів.

4. We can do this if we open our souls instead of hardening our hearts. - Ми зможемо зробити це, якщо відкриємо свої душі замість того, щоб робити жорстокими серця. Вдаємося до абсолютного відповідника в першому випадку та відносного відповідника - метафори з наближеним значенням, у другому, щоб зберегти прагматичний потенціал та стилістичну окрасу висловлювання.

3 метою підсилення свого послання до американців щодо об'єднання та досягнення більшої стилістичної експресії Дж. Байден цитував уривки з Біблії й ідеї відомих мислителів, зокрема i св. Августина, американського президента Авраама Лінкольна, навіть поезію Ленгстона Хьюза. Проілюструємо це на прикладах:

Weeping may endure for a night but joy comes in the morning.

Цей біблійний афоризм $є$ уривком Псалма Давида, який українською звучить так:

"Співайте Господеві, святії Його,

Й славте память святині Його!

Бо хвилю триває Він у гніві Своїм,

Все життя у Своїй ласці: буває

Увечорі плач, а радість на ранок! (Пс. 30: 5-6).

Використанням біблійної метафори у своєму зверненні до нації Джо Байден прагнув досягти реалізації декількох комунікативно-прагматичних завдань. 3 одного боку, він хотів наблизитись до частини віруючих американців, імпліцитно заявляючи про свою доброчесність, а з іншого - таким фігуральним способом дати надію своїм громадянам на краще майбутнє, яке прийде на зміну важким часам. Звернемося до ще одного прикладу:

Through the Civil War, the Great Depression, World War, 9/11, through struggle, sacrifice, and setbacks, our "better angels" have always prevail.

Використана метафора $є$ прецедентним феноменом, оскільки відсилає слухача до відомої промови Авраама Лінкольна: "We are not enemies, but friends. We must not be enemies. Though passion may have strained, it must not break our bonds of affection. The mystic chords of memory will swell when again touched, as surely they will be, by better angels of our nature" [13]. Метафору better angels of our nature та iï інтерпретацію в контексті промови Дж. Байдена варто перекласти відносним еквівалентом - наші світлі ангели, наші добрі ангели, наші ангели світла, або метафорою $з$ іншим образом - наші воїни світла, що $€$ семантичним аналогом.

Важкі, непрості часи, часи випробувань, про які згадує Джозеф Байден у своєму зверненні, також знайшли своє відображення у формі різноманітних метафоричних засобів:

$<\ldots>$ we have much to do in this winter of peril and possibility - період страху / відчаю та можливостей.
We will need all our strength to persevere through this dark winter - пережити цю непросту зиму / витримати ці важкі часи.

Will we master this rare and difficult hour? - Чи впораємося ми в ці важкі часи? / Чи здолаємо ми ці важкі випробування?

Метафоризація американської історії новообраним американським президентом подається у вигляді концептуальної метафори HISTORY IS A STORY:

Let us add our own work and prayers to the unfolding story of our nation.

$<\ldots>$ we will write the next chapter in the American story.

It's a story that might sound something like a song that means a lot to me.

And together, we shall write an American story of hope, not fear $<\ldots>$.

Переклад українською в такому разі буде здійснюватися за допомогою абсолютного еквівалента, 3 повним збереженням використаного образу, хоча в концептуальному відношенні англ. story більше відповідає укр. історія (у значенні history). Паралельно персоніфікація історії породжує ще одну концептуальну метафору - HISTORY IS A PERSON:

May this be the story that guides us.

The story that inspires us.

The story that tell ages yet to come that we answered the call of history.

У наведених вище прикладах доцільно використати дослівний переклад, який збереже стилістичний та прагматичний ефекти виголошених висловлювань.

У своєму інавгураційному зверненні до американського народу Джо Байден торкається теми закону, справедливості та демократії - цінностей, які, на його думку, є вразливими та потребують захисту: We have learned again that democracy is precious. Democracy is fragile. В основі його висловлювань простежується концептуальна метафора DEMOCRACY IS A WAR. Наприклад:

1. We face an attack on democracy and on truth. Напад на демократію (аналогова метафора-кліше).

2. Violence sought to shake this Capitol's very foundation. - Насильство намагалося розхитати саму основу Капітолія (дослівний переклад індивідуально-авторської метафори).

3. And here we stand, just days after a riotous mob thought they could use violence to silence the will of the people, to stop the work of our democracy, and to drive us from this sacred ground. $-<\ldots>$ бунтівна юрба вирішила, що вона насильством заглушить волю народу, зупинить демократію, вижене нас із цієї священної землі. Під час перекладу зберігаємо вжитий метафоричний образ з окремими семантичними та структурними трансформаціями, що не шкодить стилістиці дискурсу. 
4. We must end this uncivil war that pits red against blue, rural versus urban, conservative versus liberal. Ми повинні покласти край цій «негромадянській» війні, де республіканці воюють 3 демократами, село 3 містом, консерватори з лібералами.

В останньому прикладі під час перекладу відбувається заміна метафоричного образу (red against blue) на неметафоричний (республіканці воюють 3 демократами) 3 метою експлікації лінгвокультурної реалії. Однак ми зберігаємо авторський неологізм («негромадянська» війна), щоб відтворити стилістичну експресію дискурсу.

У заключній частині свого послання до американських громадян Джозеф Байден висловлює сподівання, що країні вдасться впоратися з усіма негараздами та кризами, вона стане взірцем для інших націй. Робить він це знову ж метафоричним способом, щоб досягти максимального стилістичного ефекту та, із прагматичного боку, додати більшої впевненості та переконливості своїм словам. А саме: That our America secured liberty at home and stood once again as a beacon to the world. Передаючи використане порівняння українською, варто уникати дослівного перекладу - світовий маяк, краще вдатися до описового методу - взірець / приклад для наслідування, або, як альтернатива, до семантичного аналога - орієнтир для всього світу, усесвітній лідер.

Висновки і перспективи подальших розробок. У підсумку можна стверджувати, що політична риторика Джозефа Байдена характеризується своїм автентичний унікальним стилем, насичена простими звертаннями, релігійними термінами та колоквіалізмами, відзначається значним рівнем метафоризації.

Ідейно-логічна структурованість інавгураційної промови новообраного 46-го президента США грунтується на реалізації таких базових концептуальних метафор, як: UNITY IS A PURPOSE, NATION IS AN ORGANISM, HISTORY IS A STORY, HISTORY IS A PERSON, DEMOCRACY IS A WAR. Актуалізація когнітивної основи відбувається шляхом використання широкого спектра метафоричних засобів, серед яких домінують індивідуально-авторські метафори, найоптимальнішим способом передачі яких є дослівний переклад із застосуванням абсолютних та відносних еквівалентів. В окремих випадках перекладачеві варто вдаватися до семантичних аналогів, структурних трансформацій, замін, опущення та додавання семантичних компонентів із метою збереження стилістичного ефекту та комунікативно-прагматичної спрямованості дискурсу.

Перспективи подальших досліджень можуть стосуватися критичного аналізу концептуальних метафор англійського політичного дискурсу, ïx категоризації в термінах теорії класифікації
Дж. Лакоффа та М. Джонсона; розширення та доповнення цієї теорії завдяки нововиявленим класам.

\section{ЛIТЕРАТУРА}

1. Shaffner C. Editorial: Political speeches and discourse analysis. Current issues in language and society. 1996. Vol. 3. № 3. P. 201-204.

2. Метафора. Академічний тлумачний словник. URL: http://sum.in.ua/s/metafora (дата звернення: 07.08.2021).

3. Метафора. Вікіпедія. URL: https:// uk.wikipedia.org/wiki/Метафора (дата звернення: 07.08.2021).

4. Schumacher H. The words that help us understand the world. URL: https://www.bbc.com/ culture/article/20200710-the-words-that-stretchhow-we-think (дата звернення: 05.08.2021).

5. Kövecses Z. Metaphor. A Practical Introduction. Oxford ; New York : Oxford University Press, 2002. $287 \mathrm{p}$.

6. Burmakova E.A., Marugina N.I. Cognitive Approach to Metaphor Translation in Literary Discourse. Language and Culture : the XXY Annual International Academic Conference, 20-22 October 2014. Procedia - Social and Behavioral Sciences, 154. 2014. P. 527-533.

7. Burkholder T.R., Henry D. Criticism of metaphor. Rhetorical criticism: Perspectives in action. Lanham : Lexingston Books, 2009. P. 97-114.

8. Lakoff G., Johnson M. Metaphor We Live By. Chicago ; L. : The University of Chicago Press, 1980. $242 \mathrm{p}$.

9. Musolff A. Metaphor and political discourse. Analogical reasoning in debates about Europe. New York: Palgrave Macmillan, 2004. 211 p.

10. Pavlikova Z. The Concept of Metaphor in Political Speeches (Metaphors in the Electoral Speeches of Donald Trump and Joe Biden in the 2020 Presidential Elections). URL: https://conferences.euba.sk/ jazykapolitika/www_write/files/2020/pavlikova. pdf (дата звернення: 10.08.2021).

11. Experts say Biden's inaugural address had folksy tone, direct message and phrase that will be remembered: "uncivil war" / The Spokesman-Review. URL: https://www.spokesman.com/ stories/2021/jan/20/experts-say-president-joe-bidens-inaugural-address/ (дата звернення: 06.08.2021).

12. Viala-Gaudefroy J. Biden's inaugural speech: a return to normalcy? URL: https:// theconversation.com/joe-bidens-inauguralspeech-a-return-to-normalcy-154124 (дата звернення: 06.08.2021).

13. Abraham Lincoln. Great Speeches / with Historical Notes by John Grafton. URL: https://www. goodreads.com/quotes/31631-we-are-not-ene- 
mies-but-friends-we-must-not-be (дата звернення: 06.08.2021).

14. Inaugural Address by President Joseph R. Biden, Jr. The White House. URL: https://www. whitehouse.gov/briefing-room/speeches-remarks/2021/01/20/inaugural-address-by-president-joseph-r-biden-jr/ (дата звернення: 05.08.2021).

\section{REFERENCES}

1. Shaffner, C. (1996). Editorial: Political speeches and discourse analysis. Current issues in language and society, Vol. 3, № 3. pp. 201-204.

2. Metaphor. Akademichnyi tlumachnyi slovnyk. Retrieved 07.08.2021 from http://sum.in.ua/s/ metafora.

3. Metaphor. Wikipedia. Retrieved 07.08.2021 from https://uk.wikipedia.org/wiki/Метафopa.

4. Schumacher, H. The words that help us understand the world. Retrieved 05.08.2021 from https://www.bbc.com/culture/article/20200710the-words-that-stretch-how-we-think.

5. Kövecses, Z. (2002). Metaphor. A Practical Introduction. Oxford ; New York : Oxford University Press, $287 \mathrm{p}$.

6. Burmakova, E.A., Marugina, N.I. (2014). Cognitive Approach to Metaphor Translation in Literary Discourse. The XXY Annual International Academic Conference, Language and Culture, 20-22 October 2014. Procedia Social and Behavioral Sciences, 154. Pp. 527-533.

7. Burkholder, T.R., Henry, D. (2009). Criticism of metaphor. Rhetorical criticism: Perspectives in action. Lanham : Lexingston Books. Pp. 97-114.

8. Lakoff, G., Johnson, M. (1980). Metaphor We Live By. Chicago ; L. : The University of Chicago Press. 242 p.

9. Musolff, A. (2004). Metaphor and political discourse. Analogical reasoning in debates about Europe. New York : Palgrave Macmillan. 211 p.

10. Pavlikova, Z. (2020). The Concept of Metaphor in Political Speeches (Metaphors in the Electoral Speeches of Donald Trump and Joe Biden in the 2020 Presidential Elections). Retrieved 10.08.2021 from https://conferences.euba.sk/jazykapolitika/ www_write/files/2020/pavlikova.pdf.

11. Experts say Biden's inaugural address had folksy tone, direct message and phrase that will be remembered: "uncivil war" / The SpokesmanReview. Retrieved 06.08.2021 from https://www. spokesman.com/stories/2021/jan/20/experts-saypresident-joe-bidens-inaugural-address/.

12. Viala-Gaudefroy J. Biden's inaugural speech: a return to normalcy? Retrieved 06.08.2021 from https://theconversation.com/joe-bidensinaugural-speech-a-return-to-normalcy-154124.

13. Abraham Lincoln. Great Speeches / Abraham Lincoln: with Historical Notes by John Grafton. Retrieved 06.08.2021 from https://www. goodreads.com/quotes/31631-we-are-notenemies-but-friends-we-must-not-be.

14. Inaugural Address by President Joseph R. Biden, Jr. The White House. Retrieved 05.08.2021 from https://www.whitehouse.gov/briefingroom/speeches-remarks/2021/01/20/inauguraladdress-by-president-joseph-r-biden-jr/. 